Proceedings

\title{
Innovative Technologies for District Heating and Cooling: InDeal Project ${ }^{\dagger}$
}

\author{
Serafeim Moustakidis ${ }^{1} * *^{\circledR}$, Ioannis Meintanis ${ }^{1}\left(\mathbb{D}\right.$, Nicos Karkanias ${ }^{1}$, George Halikias ${ }^{1}$, \\ Elise Saoutieff $^{2}{ }^{\circ}$, Pierre Gasnier ${ }^{2}{ }^{\circledR}$, Javier Ojer-Aranguren ${ }^{3}$, Athanasios Anagnostis ${ }^{4}$, \\ Bartosz Marciniak $^{5}{ }^{\oplus}$, Isabelle Rodot ${ }^{6}$, Emil Lezak ${ }^{7}$, Jakub Pluta ${ }^{7}$, Mladen Penev ${ }^{8}$, \\ Hilkka Jäppinen ${ }^{8}$, Samuel Petit ${ }^{9}$, Marko Krajnc ${ }^{10}$, Kostas Kouvaris ${ }^{11}$ \\ and Anastasia Eleftheriou ${ }^{11}$
}

1 City University of London, Systems \& Control Research Centre, Northampton Square,

London EC1V 0HB, UK; ioannis.meintanis.1@city.ac.uk (I.M.); n.karcanias@city.ac.uk (N.K.); g.halikias@city.ac.uk (G.H.)

2 Univ. Grenoble Alpes, CEA, LETI, DSYS, LAIC, 38000 Grenoble, France; elise.saoutieff@cea.fr (E.S); pierre.gasnier@cea.fr (P.G.)

3 NAITEC, c/Tajonar, 20, 31006 Pamplona (Navarra), Spain; jojer@naitec.es

$4 \mathrm{CERTH/IBO}$, Center for Research and Technology Hellas, Institute of Bio-Economy \& Agri-Technology, GR 57001 Thessaloniki, Greece; a.anagnostis@certh.gr

5 PROMAR Ltd., ul. Kościuszki 27, 85-079 Bydgoszcz, Poland; bartosz.marciniak@promar.com.pl

6 Société d'Équipement de la Region Montpelliéraine (SERM), Etoile Richter, 45 Place Ernest Granier, 34960 Montpellier, France; isabelle.rodot@serm-montpellier.fr

7 IZNAB Sp. z o.o., Al. Jana Pawla II 23, 00-854 Warsaw, Poland; emil.lezak@iznab.pl (E.L.); jakub.pluta@iznab.pl (J.P.)

8 NET TECHNOLOGIES FINLAND Oy, Leikosaarentie 27C, FIN-00990 Helsinki, Finland; penev@nettechn.com (M.P.); hilkka@nettechn.com (H.J.)

9 Fédération des Services Energie Environnement, 28 rue de la Pépinière, 75008 Paris, France; spetit@fedene.fr

10 Energetika Projekt d.o.o., Vransko 66a, 3305 Vransko, Slovenia; m.krajnc31@gmail.com

11 Centre for Technology Research \& Innovation, Thessalonikis 1 Str., Nicolaou Pentadromos Center, Limassol 3025, Cyprus; k_kouvaris@hotmail.com (K.K.); eleftheriouanastasia@gmail.com (A.E.)

* Correspondence: serafeim.moustakidis.1@city.ac.uk

† Presented at the EnerGaia Energy Forum, Montpellier, France, 12 December 2018.

Received: 21 January 2019; Accepted: 12 February 2019; Published: 15 February 2019

check for updates

\begin{abstract}
The paper discusses the outcomes of the conference organized by the InDeal project. The conference took place on 12 December 2018 in Montpellier as part of the EnerGaia energy forum 2018. A holistic interdisciplinary approach for district heating and cooling (DHC) networks is presented that integrates heterogeneous innovative technologies from various scientific sectors. The solution is based on a multi-layer control and modelling framework that has been designed to minimize the total plant production costs and optimize heating/cooling distribution. Artificial intelligence tools are employed to model uncertainties associated with weather and energy demand forecasts, as well as quantify the energy storage capacity. Smart metering devices are utilized to collect information about all the crucial heat substations' parameters, whereas a web-based platform offers a unique user environment for network operators. Three new technologies have been further developed to improve the efficiency of pipe design of DHC systems: (i) A new sustainable insulation material for reducing heat losses, (ii) a new quick-fit joint for an easy installation, and (iii) a new coating for reducing pressure head losses. The results of a study on the development and optimization of two energy harvesting systems are also provided. The assessment of the environmental, economic and social impact of the proposed holistic approach is performed through a life cycle analysis. The validation methodology of the integrated solution is also described, whereas conclusions and future work are finally given.
\end{abstract}


Keywords: InDeal project; control; forecasting; artificial intelligence; energy storage modelling; advanced metering; insulation materials; pipe system design; energy harvesting; web-based platform

\section{Introduction}

Energy is considered as a strategic commodity that shapes the world economy and constitutes one of the main indicators of economic competitiveness and employment. Today's societies constantly ask for more energy, while the consequences of the changes of the climate are more than evident because of the current fossil-fuel based economies. More than half (54\%) of Europe's primary energy sources are imported from outside its zone [1]. This percentage is expected to rise up to $60 \%$ by 2020, and possibly to $70 \%$ by $2030[1,2]$. District heating and cooling could play a crucial role to remedy this increasing energy imports dependency by replacing imported energy with local resources and at the same time reducing significantly the overall primary energy needs. DHC networks provide a smart, sustainable and inclusive infrastructure that is capable to adapt to potential uncertainties associated with climatic emergencies providing high levels of reliability in energy supply [3]. DHC systems and technologies can lead to primary energy and carbon emission reductions making use of various energy conversion processes for heat losses recycling. A transition from the current fossil fuel-based DHC systems into future fourth generation sustainable energy systems requires holistic approaches that allow large-scale integration of renewables along with new technologies for pipe design and insulation, as well as the application of intelligent monitoring and control tools [4].

The H2020 European project InDeal [5] (Innovative technology for district heating and cooling) is an innovative project focused on the development of energy-efficient, eco-friendly and cost-effective solutions for district heating and cooling systems (DHCS). The project's goal is to lower energy demand for DHC and to improve systems' efficiency by creating the tools for better system monitoring what can lower energy losses and reduce bills for the consumers. InDeal is a project funded by the Horizon 2020 Framework Program (topic: H2020-EE-2015-2-RIA) of the European Union under grant agreement no. 696174 . The project brings together a number of organizations from different sectors (Table 1), such as research organizations with expertise in control, machine learning, materials and energy harvesting, industrial partners with wide experience in software development, smart meters and system integration, as well as district heating and cooling services providers. Real case studies will be hosted by two network operators in France and Slovenia in order to test the sub-systems and the final system of InDeal under operational conditions.

A number of recent studies [6-8] emphasize that Europe's district heating and cooling systems must undergo a radical change into low-temperature district heating networks interacting with low energy buildings, as well as becoming an integrated part of smart energy systems. Towards this direction, the InDeal project offers a holistic solution (Figure 1) addressing the majority of the technological challenges encountered in today's DHCS. Specifically, the project offers an innovative platform that will impose a fairly distribution of heating and cooling $(H \& C)$ among the network's substations by:

- Real-time monitoring of energy consumption via artificial intelligence enabled meters;

- Short-term weather and energy demand prediction using advanced deep learning algorithms;

- Energy storage monitoring, modeling and prediction;

- Intelligent control algorithms for optimal scheduling of production units and distribution of loads that guarantee economic performance and energy efficiency;

- The $24 / 7$ monitoring of the district heating and cooling system by a user-friendly central control platform;

- Energy harvesting solutions to enable future deployment of autonomous sensors; 
- Novel pipe design solutions and innovative insulation materials to minimize distribution heat losses.

Table 1. The consortium of InDeal.

\begin{tabular}{lll}
\hline Partner. & Role & Country \\
\hline City University London (CITY) & Control and machine learning (Coordinator) & UK \\
\hline NAITEC & Materials and piping system & Spain \\
\hline Centre for Research and Technology_Hellas (CERTH/IBO) & Energy storage modeling & Greece \\
\hline $\begin{array}{l}\text { The French Alternative Energies and Atomic Energy } \\
\text { Commission (CEA) }\end{array}$ & Energy harvesting & France \\
\hline IZNAB Sp. z o.o. (IZNAB) & Life Cycle Analysis, dissemination, exploitation & Poland \\
\hline Center for Technology Research and Innovation (CETRI) & Data-driven forecasting algorithms & Cyprus \\
\hline Net Technologies Finland (NET) & IT, web-platform & Finland \\
\hline PROMAR Ltd. (PROMAR) & Smart meters, system integration & Poland \\
\hline Energetika Projekt d.o.o. (ENERGETIKA) & DH network operator & Slovenia \\
\hline $\begin{array}{l}\text { Syndicat national du chauffage urbain et de la climatisation } \\
\text { urbaine (SNCU) }\end{array}$ & $\begin{array}{l}\text { French national district heating and cooling } \\
\text { association/dissemination }\end{array}$ & France \\
\hline Société d'Équipement de la Region Montpelliéraine (SERM) & DHC network operator & France \\
\hline
\end{tabular}

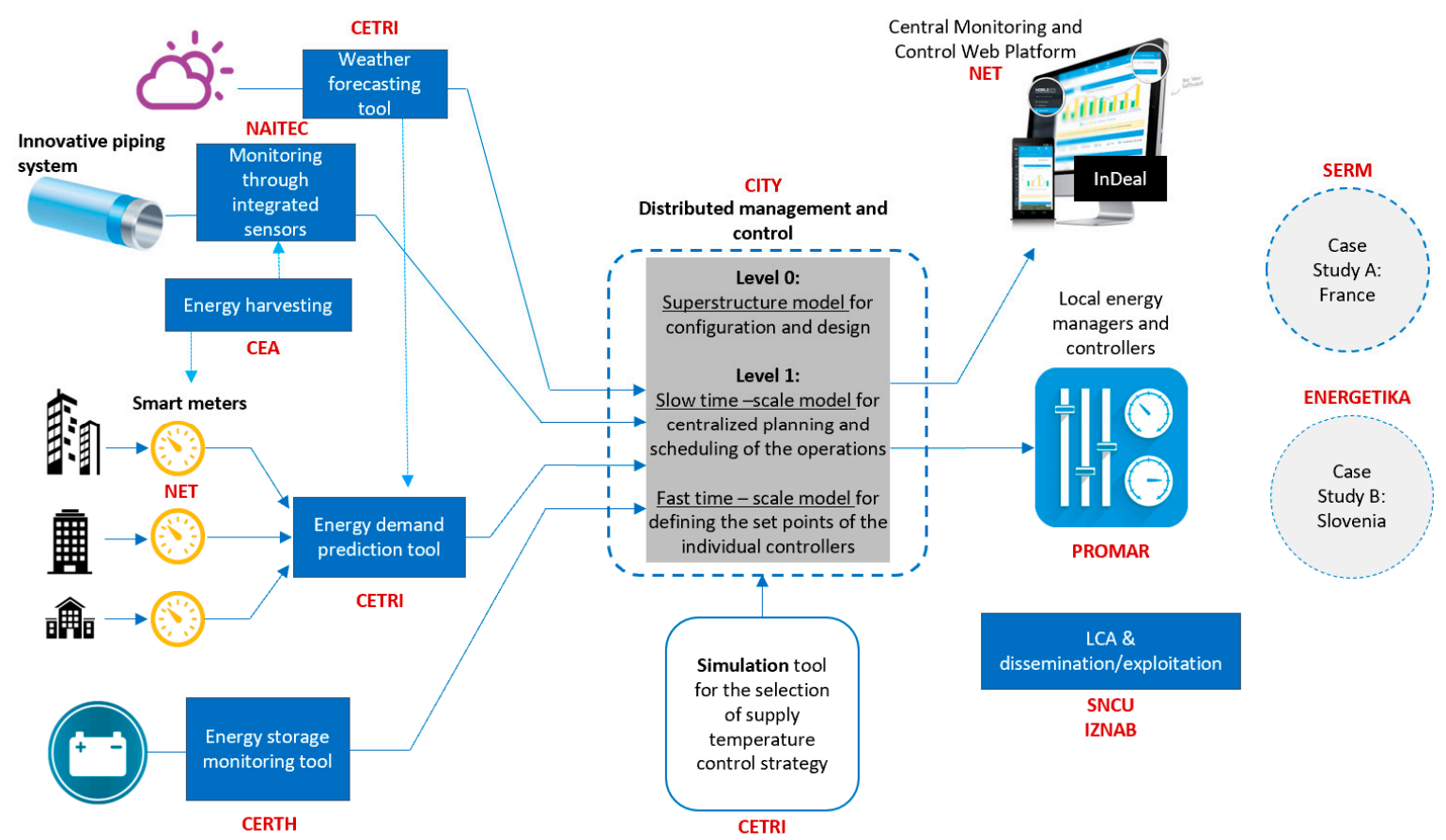

Figure 1. The integrated InDeal solution.

The aim of this paper is to present the outcomes of the InDeal conference and at the same time stimulate a discussion on the future challenges of the DHC sector towards more energy efficient and intelligent automated solutions. The rest of the paper is organized as follows: Section 2 presents the individual advancements of the different system components (sub-systems) as discussed and presented in the conference. The validation methodology of the integrated solution is given in Section 3. Conclusions and future directions are provided in Section 4.

\section{Key Innovations of InDeal}

The technological achievements of the partners, as discussed during the conference, are briefly presented below. 


\subsection{Multi-Layer Control and Modelling Framework}

The InDeal design tool aims to minimize the total plant production costs and distribute heating/cooling in a large number of buildings in a district under uncertainties in the energy demand and weather while satisfying the load demand from the end-users. The proposed control architecture employs a multi-layered structure that allows for a decomposition of the large-scale optimal control problem in smaller subproblems that are tractable and computationally efficient. Each layer addresses a different decision/control problem working at different time-scale/resolution and has its own cost function and constraints. The couplings and interactions between the decision variables and constraints at the various levels are defined by the hierarchical control structure.

More precisely, the control framework consists of:

Superstructure model: At the higher control layer, a superstructure model handles all the strategic decisions for the efficient management of the DHC system. It is implemented as a constrained optimization problem with mixed binary and continuous decision variables.

The decision problem at this layer provides a unit commitment and economic load dispatch strategy for the overall DHC system. As a cost criterion, a custom objective function that reflects the energy production costs and the variable running costs of the plant has been designed. The decision algorithm takes into account constraints, such as:

(a) Energy balance between production and customer demand;

(b) Production units' capacities;

(c) Minimum up/down time that a boiler should be kept on/off;

(d) Temperature limits per each generation unit;

(e) Ramp limits (up/down) per each production unit;

(f) Thermal energy storage dynamics and physical constraints; and

(g) Reliability constraints.

Slow time-scale model: At the middle-layer a slow time-scale model captures the continuous dynamics of the system, e.g., the transported water in the $\mathrm{DH}$ pipelines and optimizes the continuous system variables, such as supply/return temperatures and mass flow at the central plant. The control algorithm receives the outputs (decision variables) from the superstructure model and provides a supply temperature control strategy that satisfies the energy balance constraint and hence the consumer satisfaction.

Fast time-scale model: A fast-time scale model has been developed for the lower control layer which deals with the basic process control and regulation at the substation level. DH substation control system is set to supply the consumer secondary-side with a preset temperature (ref. set point) that is dependent on the outdoor temperature through a heat curve. The control system has been designed to guarantee its operational stability and achieve the desired substation performance.

The design tool receives as exogenous inputs the information from the artificial intelligence (AI)-based supporting tools regarding the weather parameters, the energy demand prediction and the available energy storage content. In order to automate the advanced control concept and solve the decision problems in near real-time, a preliminary integration plan has been designed that allows for reliable data exchange between the modelling/control framework and the information captured by the AI-based supporting tools. More information about the proposed control framework can be found in [9].

\subsection{AI-Based Supporting Tools for Weather, Energy Demand Prediction and Energy Storage Modelling}

A two-stages machine learning (ML) approach was implemented to predict the DHC users' energy needs. The methodology relies on readings from smart meters and contextual information, such as weather historical data and forecasted parameters. Specifically, the methodology comprises of: (i) A weather forecasting unit that is trained on local weather data (many years of historical data) and 
predicts future weather parameters within a horizon of $24 \mathrm{~h}$ at maximum, and b) a short-term, real-time energy demand prediction unit that makes use of both weather predictions and energy consumption historical data in order to predict accurately the forthcoming consumers' energy needs within the same time horizon of $24 \mathrm{~h}$. Specifically, long short-term memory (LSTM) networks [10] were trained using historical data from both sites, such as day of the week, time of day, current/previous energy consumption and forecasted weather parameters. The trained model was able to estimate the future energy consumption of the DHC networks for the next hours with a mean square error (MSE) of less than 0.1 for both plants in Vransko and Montpellier.

CERTH/IBO developed an ML model for the operation of a heat storage tank, located in Vransko Slovenia. An energy storage framework was established where each component involved in the production, exchange and storage of energy was modelled separately, including solar panels, a heat exchanger and a biomass boiler. Subsequently, the generated submodules were interconnected in order to model the entire operation. Advanced machine and deep learning algorithms were tested and evaluated based on their performance in modeling each component separately, as well as the framework as a whole. Random forest [11] outperformed all other algorithms and thus was selected and implemented for the modelling of all the components. The model managed to achieve a final $0.5 \%$ error in predicting the output temperature of the storage tank, with a less than $5 \mathrm{~min}$ of total runtime.

\subsection{Advanced Metering Infrastructure}

PROMAR developed advanced data metering devices with a modular design and wide range of extensions providing scalability and easy adaptation to various type of equipment in a given controlled installation. The devices are used for telemetric data acquisition from the supported building/substation and enable remote change of the functioning parameters of the connected devices. They are plugged-in directly to meters, sensors and automatic equipment and are capable to extend their functionality. The devices transform regular meters into AI meters and allow the real-time reaction to user-defined alerts. The operating system of the devices is developed to meet the project requirements and has the possibility to be upgraded remotely from the configuration server. It adds some enhancements to existing metering devices i.e., schedule of various appliance usage, supervision of supplied power and power quality diagnosis, short-term load forecasting, revenue-grade payment capabilities, such as load profiling, time-of-use, display of energy consumption. The advanced metering devices were installed in both DHC networks (in Vransko and Montpellier) collecting information about all the crucial heat substations 'parameters including pressure, temperature, current and average flow, current power and characteristics of the pumps.

\subsection{Insulation Materials and Piping System Design}

NAITEC has developed three new technologies to improve the efficiency of pipe design of DHC systems: A new sustainable insulation material for reducing heat losses, a new quick-fit joint for an easy installation, and a new coating for reducing pressure head losses. An eco-friendly insulation material based on nanocellulose was obtained with an improvement of $11 \%$ in heat losses with respect to the current PUR solution that is used in DHC pre-insulated pipes. A new quick-fit joint design was also developed with the potential to substitute the current welded joint in rigid pipe solution, with the advantages of easy installation, no requirements of special equipment, no leakage under hard working conditions and capacity of absorbing thermal expansion of the pipeline. Finally, a new internal pipe coating with anti-adherent properties was developed to reduce pressure head losses, caused by roughness in the short term, and by scale deposition and corrosion during the system performance in the long term.

\subsection{Energy Harvesting}

CEA developed two energy harvesting system, one water flow energy harvester and one thermal energy harvester. These systems make smart flow meters able to work for years without any human 
intervention by replacing batteries and improve the quality and to reduce the costs of water networks monitoring (flowrate, temperature, pressure, leakage detection, $\mathrm{pH}$ meters).

This study $[12,13]$ is the first to propose the optimization of a centimeter-scale water flow harvester, as well as its long-term characterization in a real application case. It shows high output power at high flow rates $\left(490 \mathrm{~mW} @ 9 \mathrm{~m}^{3} \cdot \mathrm{h}^{-1}\right)$ in both cold and hot water with very low-pressure losses ( $\left.<50 \mathrm{mbars}\right)$. The proportionality between the rotation speed of the turbine and the flow can be used to turn this energy harvester into an autonomous flowmeter. Besides, thermal energy harvester shows high output power at high temperature gradient (peak at $34.8 \mathrm{~mW}$ with $\Delta \mathrm{T}=38^{\circ} \mathrm{C}$ ).

\subsection{Web-Based Platform}

Net Technologies (NET) presented the progress over the development of the Central Monitoring and Control web Platform (CMCP) which hosts and visualizes all the different subtools and systems developed within the project. The goal of the $\mathrm{CMCP}$ is to offer a unique user environment which will not only present the measurable parameters of the DHCS but will also act as a transfer mechanism between the InDeal technical solutions for energy efficiency improvements. The proposed CMCP enables the end users to clearly evaluate the benefits of adopting InDeal design and innovations into their DHC networks. The main characteristics of the CMCP are summarized, as follows: (i) It has a scalable architecture, independent of any operating and database manager system; (ii) CMCP does not depend on the end user hardware/software (computer, laptop, smart phone); (iii) it enables web based access which allows connectivity anytime anywhere; (iv) it provides notification and alarming functionalities based on user needs and user access rights; (v) it integrates statistical and reporting functionalities and (vi) it is based on a security-enabled and privacy-enabled design in order to guarantee the confidentiality of the access and data within the platform.

\subsection{Life Cycle Analysis}

IZNAB performed a life cycle assessment (LCA) study in order to provide detailed data about the environmental, economic and social impact of the InDeal project's solutions. The impact assessment was divided in two parts: (i) Analysis of the environmental and economic impact comparing the new cellulose nano-fiber insulation material with the most commonly used PUR insulation and (ii) analysis of the environmental, economic and social impact of DHC plants (in Vransko and Montpellier). To assess the impact of DHC plants' data with respect to emissions, used fuels, distributed H\&C power were provided by the plants' operators (ENERGETIKA and SERM) and further analyzed by IZNAB using specialized LCA software-SimaPro [14]. The comparison was performed with the data obtained before and after the implementation of the InDeal solution in both real case study plants. Regarding the insulation material NAITEC, that is responsible for its development and testing, provided data about the materials and the energy used in the production process, their cost, as well as information about the waste generated during the production. IZNAB analyzed the data and compared it with the production process of PUR materials for pre-insulated pipes also using the SimaPro software.

The social impact assessment of the InDeal system was carried out focusing on three stakeholder categories: Workers, value-chain actors, and local communities. The analysis for Vransko and Montpellier case-studies revealed that the risk of undesired impact is low (or even very low) and that the impact of the InDeal technology may be further strengthened in the future to achieve higher levels of energy efficiency. This could be achieved by exploring how the data obtained from national smart metering platform could be used to (i) develop personalized recommendations for saving energy; (ii) more targeted policy interventions; (iii) measure actual building performance and (iv) develop compliance and enforcement measures.

\section{Validation for the Integrated Solution}

Apart from the individual assessments of all the proposed technologies (as are briefly presented in Section 2), the consortium is working on the validation of the efficiency of the integrated InDeal 
system in terms of cost reductions within the real operation of two DHC networks. The methodology adopted here for a fair and accurate demonstration of the proposed system is the following.

- Step 1: At a given time $t$, we record all the set-points of the system. We observe the operation of the system for a time period of $\Delta \mathrm{t}$ and a cost estimation is performed corresponding to the specific time period.

- Step 2: At the same time $t$, we run the InDeal solution that generates the optimal set-points of the network. We perform the same cost analysis using the selected new set-points for the same time period $\Delta \mathrm{t}$.

- Step 3: A cost comparison is performed between the existing operation of the system and the proposed scheduling by InDeal.

- $\quad$ Step 4: The same process is repeated for a long period and the overall cost figures are calculated for both approaches (the control strategy that is currently adopted versus the proposed one by InDeal).

- Step 5: After the end of the testing period, the proposed control scheduling of the InDeal solution will be integrated to act directly on both networks.

The DHC network of Odysseum in Montpellier [15] and the DH network of Vransko [16] have been selected in order to perform test assessment in the operational environment of the sub-systems and the integrated InDeal system. A detailed description of the test sites is given in [5].

\section{Conclusions and Future Directions}

The paper presents the advancements of the InDeal project. The project brings together a number of complementary technologies, including smart meters, information, communication systems, advanced analytics, machine learning and control, as well as insulation materials, piping systems and harvesting solutions. Towards the ultimate goal of optimizing the current DHC networks, the proposed technologies were tested in the plants of Vransko and Montpellier and the results of the individual components were briefly discussed. The applicability of our proposed control solution was demonstrated using energy demand data collected by the smart meters on the field. The AI-based supporting tools were proved to be useful by: (i) Estimating the future energy consumption of the DHC networks for the next hours with a mean square error (MSE) of less than 0.1 and (ii) predicting the output temperature of the storage tank with a $0.5 \%$ estimation error. An improvement of $11 \%$ in heat losses was achieved by the proposed nanocellulose material with respect to PUR that is currently used in DHC pre-insulated pipes. A new quick-fit joint design was also proposed and a new internal pipe coating with anti-adherent properties was developed to reduce pressure head losses. Two harvesters were manufactured and tested. The water flow harvester showed high output power at high flow rates $\left(490 \mathrm{~mW} 99 \mathrm{~m}^{3} \cdot \mathrm{h}^{-1}\right)$ in both cold and hot water with very low-pressure losses ( $\left.<50 \mathrm{mbars}\right)$, whereas the thermal energy harvester achieved a peak at $34.8 \mathrm{~mW}$ with $\Delta \mathrm{T}=38^{\circ} \mathrm{C}$. Finally, the social impact assessment of the integrated system and the final web platform was carried out focusing on three stakeholder categories: Workers, value-chain actors, and local communities.

Future work includes the overall validation of the integrated InDeal system following the aforementioned 5-step methodology (as presented in Section 3). The consortium also plans to validate the robustness of the proposed approach over a number of uncertainties associated with exogenous factors. To achieve this, the effect of the weather and energy demand forecasting error on the control performance will be assessed through the use of stochastic controllers' variants. The AI-based energy storage modeling module will be integrated within the controller as a means to capture the current storage capacity of the DH network. Future directions also include the application of the energy storage modelling not only to quantify the current capacity of the energy storage tank but also predict its future capacity within a time horizon of a few days. A crucial future step is the final integration of the control framework and the supporting technologies in a web platform that will be user-friendly and will allow optimal decision making and planning. The authors are planning to conduct a feasibility 
study for the potential use and applicability of the new piping system with autonomous sensing capabilities through the use of energy harvesting. Overall, InDeal project shows unique potential for the transformation of current DHCS into next-level automated networks following a holistic approach that guarantees the increase of the overall energy efficiency accomplishing a fairly distribution of $\mathrm{H} \& \mathrm{C}$ based on the estimated energy demand.

Author Contributions: Writing-original draft preparation, review and editing, S.M.; Multi-layer control and modelling framework, I.M., G.H. and N.K.; Energy storage modelling, A.A.; Advanced metering infrastructure, B.M.; Insulation materials and piping system design, J.O.; Energy harvesting, E.S. and P.G.; Web-based platform, M.P. and H.J.; Life Cycle Analysis, J.P. and E.L.; Use case A, I.R. and S.P.; Use case B, M.K.; forecasting modules, K.K. and A.E.

Funding: This research was funded by the European Union's Horizon 2020 research and innovation program under Grant Agreement \#696174: Innovative Technology for District Heating and Cooling (InDeal).

Conflicts of Interest: The authors declare no conflict of interest.

\section{Abbreviations}

The following abbreviations are used in this manuscript:

$\begin{array}{ll}\text { DHCS } & \text { District Heating and Cooling System } \\ \text { DH } & \text { District Heating } \\ \text { DHS } & \text { District Heating System } \\ \text { H\&C } & \text { Heating and Cooling } \\ \text { LSTM } & \text { Long Short-Term Memory } \\ \text { ML } & \text { Machine Learning } \\ \text { AI } & \text { Artificial Intelligence } \\ \text { MSE } & \text { Mean Square Error } \\ \text { PUR } & \text { Polyurethane } \\ \text { CMCP } & \text { Central Monitoring and Control web Platform } \\ \text { LCA } & \text { Life Cycle Analysis }\end{array}$

\section{References}

1. District Heating and Cooling-A Vision towards 2020-2030-2050. Available online: https://www.euroheat. org/wp-content/uploads/2016/04/DHC-Vision-for-DHC-2012.pdf (accessed on 13 February 2019).

2. Pezzutto, S.; Toleikyte, A.; De Felice, M. Assessment of the Space Heating and Cooling Market in the EU28: A Comparison between EU15 and EU13 Member States. Int. J. Contemp. Energy 2015, 1. [CrossRef]

3. Wiltshire, R. Advanced District Heating and Cooling (DHC) Systems; Elsevier: Amsterdam, The Netherlands, 2016.

4. Rezaie, B.; Rosen, M. District heating and cooling: Review of technology and potential enhancements. Appl. Energy 2012, 93, 2-10. [CrossRef]

5. European H2020 Project InDeal. Available online: http:/ / www.indeal-project.eu/ (accessed on 13 February 2019).

6. Connolly, D.; Lund, H.; Mathiesen, B.V.; Werner, S.; Möller, B.; Persson, U.; Boermans, T.; Trier, D.; Østergaard, P.A.; Nielsen, S. Heat roadmap Europe: Combining district heating with heat savings to decarbonise the EU energy system. Energy Policy 2014, 65, 475-489. [CrossRef]

7. Costa, A.; Loureiro, T.; Passerini, F.; Lopez, S.; Pietrushka, D.; Klepal, M.; Halikias, G.; Meintanis, I.; Moustakidis, S.; Karcanias, N.; et al. Development of Future EU District Heating and Cooling Network Solutions, Sharing Experiences and Fostering Collaborations. Proceedings 2017, 1, 1105. [CrossRef]

8. Lake, A.; Rezaie, B.; Beyerlein, S. Review of district heating and cooling systems for a sustainable future. Renew. Sustain. Energy Rev. 2017, 67, 417-425. [CrossRef]

9. Moustakidis, S.; Meintanis, I.; Halikias, G.; Karcanias, N. An Innovative Control Framework for District Heating Systems: Conceptualisation and Preliminary Results. Resources 2019, 8, 27. [CrossRef]

10. Gers, F.A.; Schmidhuber, J.; Cummins, F. Learning to forget: Continual prediction with LSTM. Neural Comput. 2000, 12, 2451-2471. [CrossRef] [PubMed]

11. Fawagreh, K.; Gaber, M.; Elyan, E. Random forests: From early developments to recent advancements. Syst. Sci. Control Eng. 2014, 2, 602-609. [CrossRef] 
12. Gasnier, P.; Saoutieff, E.; Soriano, O.; Alessandri, B.; Ojer-Aranguren, J.; Boisseau, S. Cm-Scale Axial Flow Water Turbines for Autonomous Flowmeters: An Experimental Study. Smart Mater. Struct. 2018, 27, 115035. [CrossRef]

13. Saoutieff, E.; Gasnier, P.; Boisseau, S.; Ojer-Aranguren, J.; Rodot, I. Performances of a cm-scale water flow energy harvester in real environment for autonomous flowmeters. In Proceedings of the 18th International Conference on Micro and Nanotechnology for Power Generation and Energy Conversion Applications (PowerMEMS 2018), Daytona Beach, FL, USA, 4-7 December 2018.

14. SimaPro-LCA Software. Available online: https:// simapro.com/ (accessed on 13 February 2019).

15. Odysseum DHC Network in Montpellier, France. Available online: https://www.serm-montpellier.fr/ (accessed on 13 February 2019).

16. DH Network in Vransko, Slovenia. Available online: http://www.energetika-projekt.eu/ (accessed on 13 February 2019).

(C) 2019 by the authors. Licensee MDPI, Basel, Switzerland. This article is an open access article distributed under the terms and conditions of the Creative Commons Attribution (CC BY) license (http://creativecommons.org/licenses/by/4.0/). 